\title{
Torsades de Pointes on Chronic Methadone Use
}

\section{Leila Hosseini, ${ }^{1,2}$ Alireza Heidari-Bakavoli, ${ }^{3}$ Najmeh Shahini, ${ }^{4,5,6}$ Sara Mashhadinezhad, ${ }^{7}$ and Sara} Hosseini ${ }^{7, *}$

\author{
${ }^{1}$ Cardiologist, North Khorasan University of Medical Sciences, Bojnurd, IR Iran \\ ${ }^{2}$ Fellowship of Echocardiography, Shaheed Rajaei Cardiovascular Medical and Research Center(RCMRC), Iran University of Medical Sciences, Tehran, IR Iran \\ ${ }^{3}$ Cardiovascular Department, Mashhad University of Medical Sciences, Mashhad, IR Iran \\ ${ }^{4}$ Psychiatry and Behavioral Sciences Research Center, Ibn-e-Sina Hospital, Faculty of Medicine, Mashhad University of Medical Sciences, Mashhad, IR Iran \\ ${ }^{5}$ Student Research Committee, Mashhad University of Medical Sciences, Mashhad, IR Iran \\ ${ }^{6}$ Golestan Psychiatry Research Center, Golestan University of Medical Sciences, Gorgan, IR Iran \\ ${ }^{7}$ Cardiologist, Mashhad University of Medical Sciences, Mashhad, IR Iran \\ "Corresponding author: Sara Hosseini, Cardiologist, Student Research Committee, Mashhad University of Medical Sciences, Mashhad, IR Iran. Tel: +98-9112700530, E-mail: \\ hosseinis841@yahoo.com
}

Received 2016 April 14; Revised 2016 August 31; Accepted 2017 March 15.

Keywords: Methadone, Prolonged QTc, ECG

\section{Dear Editor,}

Methadone is a drug associated with the development of prolonged Correcred QT (QTc) interval, as QT interval prolongation can occur in up to $15 \%$ of methadonemaintenance patients. In recent years, methadone found to be associated with an increased risk of sudden death in a community-based study $(1,2)$. "Torsades de Pointes" is a quick and dangerous rhythm that quickly becomes ventricular fibrillation. If this rhythm is rapid or prolonged, it can lead to ventricular fibrillation or sudden cardiac death. The usual clinical manifestations of TdP are palpitations, dizziness, and syncope. It is certain that no cardiac drugs are recognized to increase the propensity for TdP. The most common risk factors of methadoneassociated QT prolongation and TdP include a high dose of methadone or chronic use, old age, accompaniment with enhancing drugs methadone levels, infections such as AIDS, old age, low potassium, kidney failure, heart disease, female gender, and cirrhosis of the liver (3). Despite the availability of methadone for over 60 years, only in the past 10 years has this medication received attention for its potential to cause QTc prolongation leading to Torsades de Pointes (4-6).

We report 4 cases of methadone-induced Torsades de pointes. Through rapid taper of methadone, the patient's ECG normalized.

Case 1: A 46 year-old man with a history of chronic methadone therapy presented with syncope. He used methadone, $15 \mathrm{cc} /$ daily and increase to $20 \mathrm{cc} /$ daily. The initial assessment includes a detailed history of heart disease and blood sample. The patient was admitted to the cardiol- ogy service for ECG monitoring. Shortly thereafter, the patient experienced frequent runs of non-sustained ventricular tachycardia culminating in an episode of Torsades de pointes. His methadone dose was reduced, followed. ECG demonstrated a prolonged QTc interval of 570 milliseconds. In consultation with the psychiatrist, methadone slowly stopped and at the time of discharge, the QTc interval was normal (less than 450 milliseconds). Case 2: A 59 year-old man to the cardiology service for recurrent syncope. He had a history of 10 years of methadone therapy, $70 \mathrm{mg}$ methadone. In ECG monitoring, the patient had a PVC bigeminy. His methadone dose was discontinued; in the follow up, QTc interval was decreased. At the time of discharge, the QTc interval was 420 milliseconds. Case 3: A 60 year-old man with a history of chronic methadone therapy (15 cc/daily for $\geq 15$ years) and an increase in 3 months to $18 \mathrm{cc} /$ day admit to the cardiology service for syncope. In ECG monitoring, the patient had a Torsades de pointes. In the follow up, after discontinuing methadone, ECG demonstrated a prolonged QTc interval of 720 milliseconds. In consultation with the psychiatrist, methadone slowly stopped. At the time of discharge, the QTc interval was 530 milliseconds. Lastly Case 4: A 37 year-old man with a history of 5 years methadone therapy (10 cc/daily) for muscoskeletal pain and increased it to 20 cc/daily before admission to the cardiology service for syncope. In ECG monitoring, the patient had a Torsades de pointes. After laying ICD, the QTc interval was 320 milliseconds (Figure 1).

Our patient was receiving a normal dose of methadone and had no other risk factors predisposing them to QTC prolongation. 


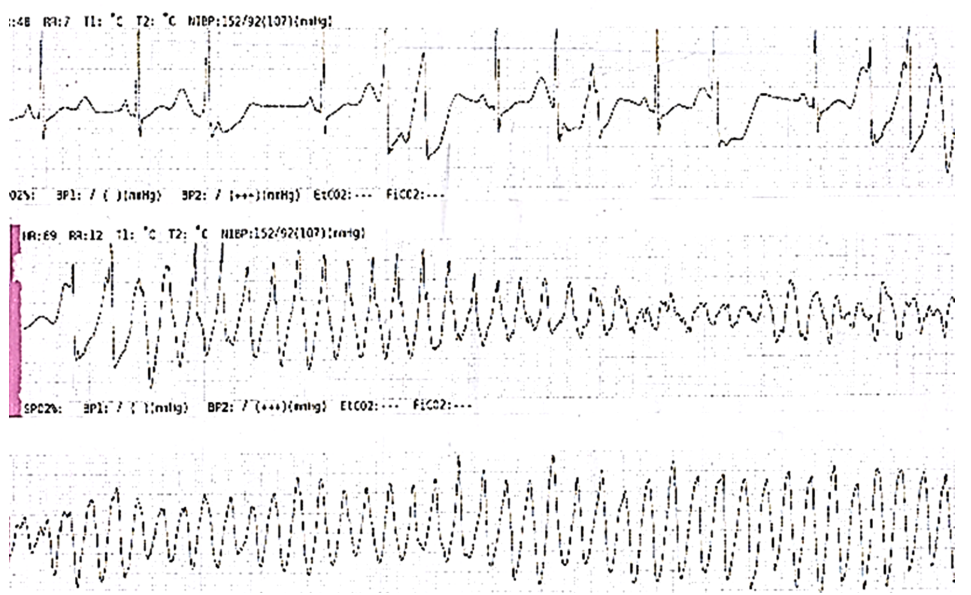

Figure 1. ECG Torsades de Pointes

Due to unpredictable of QT prolongation and Torsades de pointes in patients with high doses of opium and high dependence who are taking high doses of methadone, alternative agents such as buprenorphine and a mixed opioid antagonist/agonist should be considered.

\section{References}

1. Chugh SS, Socoteanu C, Reinier K, Waltz J, Jui J, Gunson K. A community-based evaluation of sudden death associated with therapeutic levels of methadone. Am J Med. 2008;121(1):66-71. doi: 10.1016/j.amjmed.2007.10.009. [PubMed: 18187075].

2. Raina S, Paydak H, Al-Lahham T, Shihabuddin BS. Methadone induced Torsades de Pointes mimicking seizures in clinical presentation. Am J Drug Alcohol Abuse. 2014;40(6):490-2. doi 10.3109/00952990.2014.965311. [PubMed: 25321151].

3. Justo D, Gal-Oz A, Paran Y, Goldin Y, Zeltser D. Methadone-associated Torsades de Pointes (polymorphic ventricular tachycardia) in opioiddependent patients. Addiction. 2006;101(9):1333-8. doi: 10.1111/j.13600443.2006.01512.x. [PubMed: 16911733].

4. Lipski J, Stimmel B, Donoso E. The effect of heroin and multiple drug abuse on the electrocardiogram. Am Heart J. 1973;86(5):663-8. [PubMed: 4743335].

5. Krantz MJ, Kutinsky IB, Robertson AD, Mehler PS. Dose-related effects of methadone on QT prolongation in a series of patients with torsade de pointes. Pharmacotherapy. 2003;23(6):802-5. [PubMed: 12820821].

6. Abramson DW, Quinn DK, Stern TA. Methadone-Associated QTc Prolongation: A Case Report and Review of the Literature. Prim Care Companion J Clin Psychiatry. 2008;10(6):470-6. [PubMed: 19287558]. 